\title{
Sedation management for standing enucleation of the left eye in a 37 years old horse with decompensated left heart failure
}

\author{
Klaus Hopster and Sabine Kästner \\ Clinic for Horses, University of Veterinary Medicine Hannover, Foundation, Hannover, Germany
}

\begin{abstract}
Summary
A 37 year old Arabian horse was presented for enucleation. Because of decompensated left heart failure and pulmonary oedema the decision for surgery in a standing position was made. The horse was sedated with acepromazine, levomethadone and xylazine and the supraorbital, lacrimal, infratrochlear and zygomatic nerve were blocked for desensitizing of the eyelids. In addition, an auriculopalpebral and a retrobulbar block were performed to obtain palpebral akinesia and to prevent the occurrence of the oculocardiac reflex. The eye was enucleated without any adverse effects with the horse standing calm and stable without any signs of pain.
\end{abstract}

Keywords: enucleation / standing surgery / local block / oculocardiac reflex / sedation

\author{
Sedierungsprotokoll für die Enukleation am stehenden Patienten bei einem 37 jährigen Pferd mit kongestivem Linksherzver- \\ sagen
}

Der vorliegende Fallbericht beschreibt die Enukleation eines Auges bei einem 37 jährigen Araber-Wallach. Nach klinischer und weiterführender kardiologischer Untersuchung wurden eine hochgradige Aortenklappeninsuffizienz und eine mittelgradige Mitralklappeninsuffizienz mit deutlicher Dilatation des linken Vorhofs und linken Ventrikels sowie der Pulmonalarterie festgestellt. Nach elektrokardiographischer Diagnostik wurde zudem Vorhofflimmern diagnostiziert. Aufgrund der vorliegenden Herzbefunde wurde von einem Eingriff in Allgemeinanästhesie abgesehen und die Enukleation am stehenden Patienten vorgenommen. Das Pferd wurde mit 0,03 mg/kg Acepromazin und $0,1 \mathrm{mg} / \mathrm{kg}$ Levomethadon sediert. Nach 15 Minuten folgte ein Bolus 0,1 mg/kg Xylazin gefolgt von einer Dauertropfinfusion mit $0,3 \mathrm{mg} / \mathrm{kg} / \mathrm{Std}$ Xylazin. Während des gesamten Eingriffs wurde eine Überwachung der Kreislaufparameter mittels EKG und Blutdruckmanschette durchgeführt. Das Auge und die umliegenden Strukturen wurden mittels Mepivacain lokal betäubt. Es erfolgten eine Anästhesie der Nervi supraorbitalis, lacrimalis, infratrochlearis und zygomaticus sowie des Nervus auriculopalpebralis. Um die Gefahr des Auftretens eines okulokardialen Reflexes zu reduzieren, wurde zudem ein retrobulbärer Block durchgeführt. Nach der Applikation von Acepromazin und Levomethadon stellte sich eine moderate Sedierung ein, die durch die Gabe von Xylazin eine für die Operation ausreichende Tiefe erreichte. Die erwarteten kardiovaskulären Nebenwirkungen des Xylazins wurden durch die vorhergehende Gabe von Acepromazin und Levomethadon auf ein vertretbares Minimum reduziert. Die verwendeten lokalen Betäubungen ermöglichten eine traspalpebrale Enukleation ohne weitere Abwehrbewegungen oder Schmerzäußerungen des Patienten.

Schlüsselwörter: Enukleation / Lokalanästhesie / olulokardialer reflex / Sedierung / stehend

\section{Introduction}

Anaesthesia for ocular procedures continues to be a challenge for the equine anaesthetist (Parviainen and Trim 2000). Important considerations include maintenance of a central eye position, an immobilised eye and avoidance of increased intraocular pressure (Collins et al. 1995). Either, a deep plane of anaesthesia is required, with potential for hypotension and hypoventilation, leading to further complications such as myopathies and prolonged or traumatic recoveries from anaesthesia or the use of neuromuscular-blocking agents, with the risk of residual neuromuscular blockade and adverse recoveries. Ocular procedures may also initiate severe blood loss, cardiac dysrhythmias, or cardiac arrest (Short and Rebhun 1980, Raffe et al. 1986, Gasthuys et al. 1988). Enucleation using a transpalpebral approach in the standing horse is described without causing severe complications like haemorrhage, bradycardia or hypotension (Hewes et al. 2007, Pollock et al. 2008).

Degenerative valvular disease of the aortic valve is common in geriatric horses (Else and Holmes 1972, Patteson and
Cripps 1993, Stevens et al. 2009) and anaesthetic management of these patients can be challenging. In the majority of horses with aortic insufficiency, the lesion is well tolerated, but especially old horses can show clinical signs of congestive heart failure (Reef and Spencer 1987). Most horses that develop congestive heart failure with degenerative aortic insufficiency have ventricular dilatation to a degree that can disrupt the mitral valve annulus and cause mitral insufficiency (Stevens et al. 2009). In humans, valvular heart disease can be associated with impaired cardiac output, and can cause pulmonary hypertension and interstitial pulmonary oedema which is exacerbated by general anaesthesia (Frogel and Galusca 2010). This case report describes enucleation in a standing 37 year old horse with decompensated left heart failure using mild sedation and local blocks.

\section{Case report}

A 37 years old Arabian horse gelding ( $380 \mathrm{~kg}$ bwt) was presented to the Clinic for Horses of the University of Veterinary Medicine in Hanover because of a deep and very painful cor- 
neal ulcer of the left eye. After information about different therapeutic options the owner decided for enucleation of the affected eye.

Abnormal findings of the clinical examination were an irregular heart rate with a mean of $84 \mathrm{~min}^{-1}$ and respiratory rate of $32 \mathrm{~min}^{-1}$. A holodiastolic heart murmur grade 4 and an early systolic heart murmur grade 3 with its point of maximal intensity over the aortic valve respectively over the mitral valve were detected. Colour flow Doppler echocardiography showed a severe aortic valvular insufficiency and a moderate mitral valve insufficieny with mitral valve prolaps and dilatation of the left artrium and ventricle and the pulmonary artery. Electrocardiographic examination showed atrial fibrillation with a ventricular response rate of $80 \mathrm{~min}^{-1}$. On auscultation end-inspiratory crackles were detected over both lung sides. Radiographs of the lungs were consistent with interstitial pulmonary oedema. Based on the clinical examination, the diagnosis of decompensated left heart failure with severe aortic and mitral insufficiency with pulmonary hypertension and pulmonary oedema was made and the physical status of the horse categorized as ASA (American Society of Anesthesiologists) 4. Due to financial limitations the owner decided against further diagnostics and preoperative therapy. Because of the increased anaesthetic risk associated with ASA 4 status, the decision for transpalpebral eye enucleation in the standing horse was made.

\section{Anaesthetic technique}

The Horse was placed in stocks and equipped with a telemetric ECG recording system (Televet 100, Rösch \& Associates, Frankfurt, Germany). Blood pressure was measured by high definition oscillometry (VET HDO Monitor ${ }^{\circledR}, \mathrm{S}+\mathrm{B}$ medVet $\mathrm{GmbH}$, Babenhausen, Germany) with the cuff placed at the base of the tail (middle coccygeal artery) every 3 minutes. The device was connected to a computer system. By real-time scanning the pulse waves were visualised on a PC screen and the algorithm was capable of capturing all of the relevant data and ignoring all pre-programmed artifacts.

A 12 gauge indwelling catheter (EquiCath ${ }^{\top M}$ Fasfflow, Braun, Tuttlingen, Germany) was placed into the left jugular vein. The horse was sedated with $0.03 \mathrm{mg} \mathrm{kg}^{-1}$ acepromazine (Vetranquil $^{\circledR} 1 \%$, Albrecht $\mathrm{GmbH}$, Aulendorf, Germany) IV, 0.1 mg kg 1 levomethadone (L-Polamivet ${ }^{\circledR}$, combination of Levomethadoni hydrochloridum $2.5 \mathrm{mg}$, Fenpipramidi hydrochloridum $0.125 \mathrm{mg}$, Intervet Deutschland $\mathrm{GmbH}$, Unterschleißheim, Germany) IV followed after 15 minutes by $0.1 \mathrm{mg} \mathrm{kg}^{-1}$ xylazine (Xylazin ${ }^{\circledR} 2 \%, \mathrm{CP}$-pharma GmbH, Burgdorf, Germany) as a slow IV bolus and a constant rate infusion (CRI) of xylazine at $0.3 \mathrm{mg} \mathrm{kg}^{-1} \mathrm{~h}^{-1}$ using a syringe driver (perfusor ${ }^{\circledR}$ compact, B. Braun Melsungen AG, Meslungen, Germany).

The eye and associated structures were desensitized using $2 \%$ mepivacaine hydrochloride (Scandicain ${ }^{\circledR} 2 \%$, AstraZeneca $\mathrm{GmbH}$, Wedal, Germany). The supraorbital, the lacrimal, the infratrochlear and the zygomatic nerve were blocked for sensory block of the eyelids and the auriculopalpebral nerve und a retrobulbar block were performed for akinesia of the eye. The supraorbital nerve was blocked by injecting $2 \mathrm{ml}$ of mepivacaine into the supraorbital foramen, $1 \mathrm{ml}$ as the needle was slowly withdrawn and another $2 \mathrm{ml}$ subcutaneously immediately over the foramen. The lacrimal nerve was blocked at the lacrimal canthus along the dorsal rim of the orbita with $3 \mathrm{ml}$ mepivacaine and another $3 \mathrm{ml}$ mepivacaine were placed around the infratrochlear nerve at the dorsal rim of the orbita near the medial canthus. The zygomatic nerve was blocked with $5 \mathrm{ml}$ mepivacaine on the lateral aspect of the bony orbit and the auriculopalpebral nerve was blocked at the ventral edge of the temporal portion of the zygomatic arch. A retrobulbar block was performed transpalpebral choosing injection site at the lateral canthus of the orbital fossa just caudal to the caudal aspect of the bony dorsal orbital rim. The slightly bended needle (18 gauge, $80 \mathrm{~mm}$ Tuohy needle, Perican ${ }^{\circledR}$, Braun, Tuttlingen, Germany) was advanced until slight dorsal movement of the eye was noticed, indicating a position at the retrobulbar muscle cone. Eight $\mathrm{ml}$ mepivacaine were deposited at this site. A total volume of $24 \mathrm{ml}$ of mepivacaine $2 \%$ was used for the local blocks.

The horse was mildly sedated after acepromazine and levomethadone, but this combination was not sufficient for the horse to tolerate performance of the local blocks which made deepening of sedation by xylazine necessary. Heart rate was $80 \mathrm{~min}^{-1}$ before sedation and remained unchanged after sedation with acepromazine and levomethadone. Immediately after the bolus of xylazine heart rate decreased to $64 \mathrm{~min}^{-1}$ followed by a slow incremental increase over time and during xylazine CRI to a maximum of $76 \mathrm{~min}^{-1}$ at the and of surgery. Baseline value of mean arterial blood pressure before medication was $72 \mathrm{mmHg}$ (systolic blood pressure $99 \mathrm{mmHg}$, diastolic blood pressure $62 \mathrm{mmHg}$ ) and decrease after injection of acepromazine and levomethadone $70 \mathrm{mmHg}$ (systolic blood pressure $92 \mathrm{mmHg}$, diastolic blood pressure $58 \mathrm{mmHg}$ ). After injection of xylazine, there was a marked increase in mean arterial blood pressure to $101 \mathrm{mmHg}$ (systolic blood pressure $135 \mathrm{mmHg}$, diastolic blood pressure $82 \mathrm{mmHg}$ ) and it decreased over time and during surgery continuously to $77 \mathrm{mmHg}$ (systolic blood pressure $101 \mathrm{mmHg}$, diastolic blood pressure $65 \mathrm{mmHg}$ ) at the end of surgery.

The eye was enucleated successfully using a transpalpebral technique and the horse was standing calm without any signs of pain, adverse reactions or heart rate and blood pressure response to incision.

\section{Discussion}

A horse with decompensated left heart failure was presented to the Clinic for Horses because of a deep, very painful corneal ulcer. Different options for therapy were discussed and owners decided for enucleation of the effected eye.

Human patients with decompensated valvular heart disease have a reduced cardiac output and a higher incidence for hypoxia than other patients (Frogel and Galusca 2010). Because of aortic and mitral valvular insufficiency leading to impaired ventricular function and decreased diastolic filling mild hypotension was noticed in our patient. In men atrial fibrillation leads to reduced cardiac output (Daoud et al. 1996). Cardiovascular function during anaesthesia is well maintained in horses with atrial fibrillation without underlying cardiac disease (Schauvliege et al. 2009). In patients with left 
heart failure cardiac output can be compromised due to left heart failure. Because of this severe hypotension would be expected during general anaesthesia because of further cardiovascular depression of the anaesthetic drugs. Treatment and management of congestive heart failure includes ACE inhibitors for afterload reduction (vasodilation), sodium and fluid loss and amelioration of myocardial remodeling (Gardner et al. 2004, Gehlen et al. 2003). In severe cases digoxin can be administered to increase force and velocity of myocardial contraction, to decrease conduction velocity through the atrioventricular node and to decrease activity of the adrenergic nervous system (Sweeney et al. 1993). Additionally

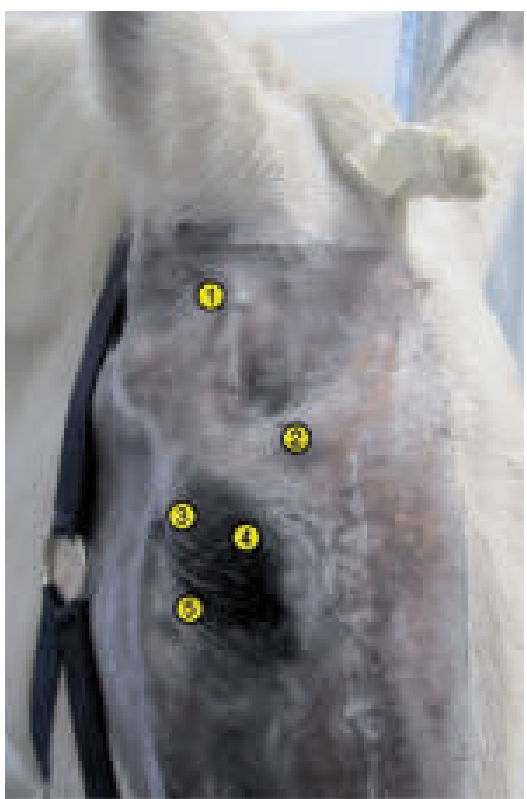

Fig. 1 Injection sides for the (1) auriculopalpebral nerve (akinesia of the upper eyelid) and the (2) supraorbital, the (3) lacrimal, the (4) infratrochlear and the (5) zygomatic nerves (sensory block of the eyelids).

Injektionsstellen zur Blockade des (1) Nervus auriculopalpebralis (Akinesie des oberen Augenlieds) sowie des (2) Nervus frontalis, (3) des Nervus lacrimalis, (4) des Nervus infratrochlearis und (5) des Nervus zygomaticus (Nerven 2-5 sind sensorische Nerven)

furosemide should be initiated to reduce congestion and lung water and lower pulmonary transcapillary pressure (Senior 2005) because pulmonary oedema impairs gas exchange and oxygen-uptake of the lungs and therefore also increases the risk of hypoxia. Therapy of both, heart failure as well as lung oedema is absolutely recommended before elective surgery to reduce anaesthetic risk. However, due to financial limitations the owners decided against preoperative treatment of left heart failure and lung oedema.

The morbidity and mortality rates for horses subjected to general anaesthesia are higher than for many other domestic species, ranging between $6.4 \%$ and $13.7 \%$ for morbidity (Richey et al. 1990, Senior et al. 2007) and between 0.12\% and $0.8 \%$ (Bidwell et al. 2007, Johnston et al. 2002) for mortality rate. Factors influencing morbidity and mortality were among other things ASA-category, cardiovascular status and the age of the horse (older horses have higher risk). Recovery from general anaesthesia is the most critical phase in equine anaesthesia because of the inability of complete control and is mainly affected by the anaesthetic conditions.
Especially horses after ocular surgery are at greater risk for unsatisfactory recoveries from anaesthesia (Parviainen and Trim 2000) compared to other elective procedures. Performing surgery in the standing and well sedated horse avoids the risk of poor recoveries and might reduce morbidity and mortality in these patients.

The decision to perform a procedure in the standing patient rather than in general anaesthesia depends on many factors, such as patient health and related anaesthetic risk, safety, comfort and experience of the surgeon and anaesthetic expertise. The risk for further damage or injury of the horse is easier
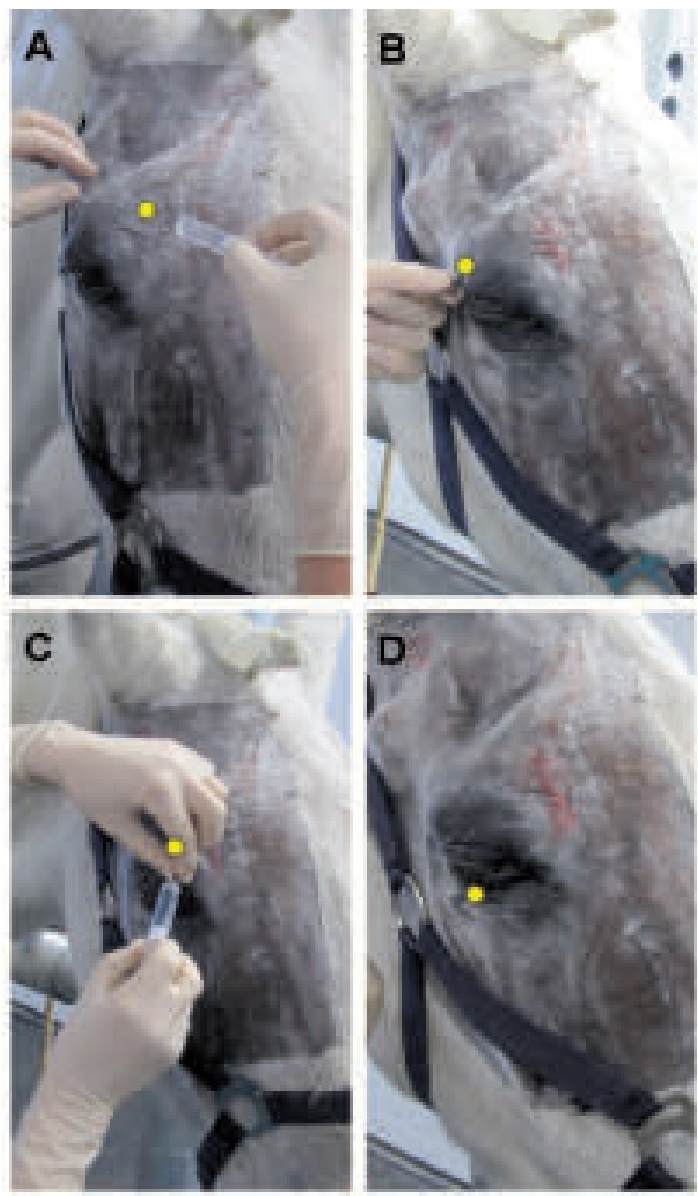

Fig. 2 Sensory block of the eye: A The supraorbital nerve was blocked by injecting $2 \mathrm{ml}$ of mepivacaine into the supraorbital foramen, $1 \mathrm{ml}$ as the needle was slowly withdrawn and another $2 \mathrm{ml}$ subcutaneously immediately over the foramen. B The lacrimal nerve was blocked at the lacrimal canthus along the dorsal rim of the orbita with $3 \mathrm{ml}$ mepivacaine. C Another $3 \mathrm{ml}$ mepivacaine were placed around the infratrochlear nerve at the dorsal rim of the orbita near the medial canthus. D The zygomatic nerve was blocked with $5 \mathrm{ml}$ mepivacaine on the lateral aspect of the bony orbit.

Durchführung der Blockade sensorischer Nerven am Auge des Pferdes. A Um den Nervus frontalis zu anästhesiesen werden $2 \mathrm{ml}$ des Lokalanästhetikums in das Foramen supraorbitale injizient, ein $1 \mathrm{ml}$ wird bei zurückziehen der Injektionskanüle im Kanal abgesetzt und weitere $2 \mathrm{ml}$ subkutan im Bereich der Einstichstelle injiziert. B Die Punktionsstelle zur Anästhesie des Nervus lacrimalis befindet sich am dorsalen Rand der Orbita, oberhalb des nasalen Augenwinkels. Hier werden $3 \mathrm{ml}$ Lokalanästhetikum in die Tiefe appliziert. C Die Punktionsstelle zur Anästhesie des Nervus lacrimalisbefindet sich ebenfalls am dorsalen Rand der Orbita, jedoch oberhalb des lateralen Augenwinkels. D Die Blockade des Nervus zygomaticus erfolgt, indem $5 \mathrm{ml}$ des Lokalanästhetikums an den ventralen Rand der knöchernen Orbita in die Tiefe applizient werden. 
to prevent during general anaesthesia and surgery in the immobilised patient is safer for the surgeon, the anaesthetist and the equipment (Wilkie 1991). In standing procedures the horse is sedated but arousable and may react to touch or noise and by definition even in deep sedation purposeful responses to painful stimuli are possible. Aseptic draping, maintaining sterility of the suture and the instruments is more difficult or is often omitted in standing surgery because of movement of the horse. Also visibility is poorer and therefore knowledge of the anatomy is more important for precise surgical dissection. As a result there is an increase in risk of infection and of poor cosmetic outcome for standing enucleation. However the increased risk for hypotension and hypoxia because of the left heart failure and the lung oedema leading to high risk of anaesthetic related mortality in combination with the increased age of this horse resulted in the decision to avoid general anaesthesia and perform enucleation in the standing horse.

Transpalpebral enucleation in the standing horse is described as eliminating the risk and costs of general anaesthesia (Po/lock et al. 2008). Proper use of nerve blocks, topical analgesia and sedative drugs are necessary to perform this technique (Wilkie 1991). Sensory denervation of the eye and the eyelids requires anaesthesia of four individual nerves: the supraorbital, lacrimal, zygomatic and infratrochlear nerve. The block of the supraorbital nerve desensitizes the forehead, including the middle two thirds of the upper eyelid and palpebral motor supply from the medial portion of the palpebral branch of the auriculopalpebral nerve (Manning and Claire 1976). Anaesthesia of the lateral cantus and the lateral aspect of the upper eyelid are achieved by blocking the lacrimal nerve and medial canthal anaesthesia is performed by blocking the infratrochlear nerve (Manning and Claire 1976). For local anaesthesia of the lower eyelid and its surrounding skin and connective tissue, the zygomatic nerve has to be blocked (Manning and Claire 1976). With these four blocks all sensitive branches of the trigeminal nerve innervating the eye are desensitized in the horse. Palpebral akinesia is achieved by blocking the auriculopalpebral nerve (Rubin 1964). As being a branch of the facial division of the trigeminal nerve it also carries motor fibres to the orbicularis muscles. Blocking this branch of the trigeminal nerve, in addition to anaesthetizing the optical nerve and the retrobulbic muscles, reduces the incidence of the oculocardiac reflex (Ludders 1994, Raffe et al. 1986). This reflex is mediated by nerve connections between the trigeminal cranial nerve and the vagus nerve of the parasympathetic nervous system. The afferent tracts are derived mainly from the ophthalmic division of the trigeminal nerve, although tracts from the maxillary and mandibular division have also been documented (Lang et al. 1991). These afferents synapse with the visceral motor nucleus of the vagus nerve, located in the reticular formation of the brain stem. The efferent portion is carried by the vagus nerve from the cardiovascular centre of the medulla to the heart, of which increased stimulation leads to decreased output of the sinuatrial node (Lang et al. 1991). Bradycardia, junctional rhythm, asystole and death can be induced through this reflex, which mainly occurs during ocular surgery during manipulation of the eye immediately before it is removed.

In this case the combination of acepromazine and levomethadon produced no adequate sedation to perform the local blocks. Acepromazine was used in this case because it pro- duces mild sedation with less reduction of locomotor activity (Muir and Hubbel 2009). In addition it has a direct vasodilatatory effect on the blood vessels (Walker and Geiser 1986) leading to a reduction of the afterload comparing to the effect of ACE inhibitors. After additional medication with xylazine the horse was well sedated and local blocking of the eye and peripheral structures as well as performing the surgery was possible. Xylazine was used in very low dose to reduce adverse cardiovascular effects like reduction in heart rate, alteration of heart rhythm, an initial hypertension followed by a prolonged hypotension and a decrease in the cardiac output (England and Clarke 1996). Cardiovascular side effects were only moderate due to the low dose, the slow application time (CRI) und the combination with acepromazine.

During surgery no signs of pain were noticed. The horse showed no adverse or aversive reactions to the stimuli and no changes in heart rate or in blood pressure resulting from the surgical procedure. Special attention was given to the direct manipulation of the eye which can potentially produce a oculocardiac reflex, but no signs of bradycardia or arrhythmia were noticed during enucleation.

\section{Conclusion}

The decision to perform a procedure with standing sedation rather than general anaesthesia must be made on basis of the temperament of the horse and skill of the veterinarian. The surgical experience in performing procedures standing is also important for a successful outcome. Although enucleation in general anaesthesia is technically easier to perform with decreased risk for infection of the wound or injury of the surgeon or anaesthetist, in this case patient risk considerations resulted in the decision for standing surgery.

\section{References}

Bidwell L. A., Bramlage L. R. and Rood W. R. (2007) Equine perioperative fatalities associated with general anaesthesia at a private practice - a retrospective case series. Vet. Anaesth. Analg. 34, 23-30

Collins B. K., Gross M. E., Moore C. P. and Branson K. R. (1995) Physiologic, pharmacologic, and practical considerations for anesthesia of domestic animals with eye disease. J. Am. Vet. Med. Ass. 207, 220-230

Covino B. G. (1986) Pharmacology Of Local Anaesthetic Agents. Br. J. Anaesth. 58, 701-716

Daoud E.G., Weiss R., Bahu M., Knight B. P., Bogun F., Goyal R., Harvey M., Strickberger S. A., Man K. C. and Morady F. (1996) Effect of an irregular ventricular rhythm on cardiac output. Am. J. Cardiol. 12, 1433-1436

Ducharme N. G. and Fubini S. L. (1983) Gastrointestinal complications associated with the use of atropine in horses. J. Am. Vet. Med. Ass. 182, 229-231

Else R. W. and Holmes J. R. (1972) Cardiac pathology in the horse. 1. Gross pathology. Equine Vet. J. 4, 1-8

England G. C. and Clarke K. W. (1996) Alpha 2 adrenoceptor agonists in the horse-a review. Br. Vet. J. 152, 641-657

Frogel J. and Galusca D. (2010) Anesthetic considerations for patients with advanced valvular heart disease undergoing noncardiac surgery. Anesthesiol. Clin. 28, 67-85

Gardner S. Y., Atkins C. E., Sams R. A., Schwabenton A. B. and Papich M. G. (2004) Characterization of the pharmacokinetic and pharmacodynamic properties of the angiotensin-converting enzyme inhibitor, enalapril, in horses. J. Vet. Intern. Med. 18, 231-237 
Gasthuys F., De Moor A., Picavet M., Muylle E. and Steenhaut M. (1988) Atrial fibrillation during eye enucleation in a horse. Vlaams Diergen. Tijdschr., 57, 207-212

Hewes C. A., Keoughan G. C. and Gutierrez-Nibeyro S. (2007) Standing enucleation in the horse: a report of 5 cases. Can. Vet. J. $48,512-514$

Gehlen H., Vieht J. C. and Stadler P. (2003) Effects of the ACE inhibitor quinapril on echocardiographic variables in horses with mitral valve insufficiency. J. Vet. Med. Physiol. Pathol. Clin. Med. 50 460-465

Johnston G. M., Eastment J. K., Wood J. L. N. and Taylor P. M. (2002) The confidential enquiry into perioperative equine fatalities (CEPEF): mortality results of Phases 1 and 2. Vet. Anaesth. Analg. $29,159-170$

Lang S., Lanigan D. and Van Der Wal M. (1991) Trigeminocardiac reflexes: maxillary and mandibular variants of the oculocardiac reflex. Can. J. Anaesth. 38, 757-760

Ludders J. (1994) Anesthesia and the ophthalmic surgical patient. In: Proceedings of the North American Veterinary Conference, pp 14-16

Manning J. P. and Clair L. E. (1976) Palpebral frontal and zygomatic nerve blocks for examination of the equine eye. Vet. Med. 71, 187-189

Muir W. W. and Hubbel J. A. E. (2009) Equine Anesthesia - Monitoring and Emergency Therapy. 2nd ed. Saunders Eslsvier, St. Louis, Missouri

Parviainen A. K. J. and Trim C. M. (2000) Complications associated with anaesthesia for ocular surgery: a retrospective study. Equine Vet. J. 32, 555-559

Patteson M. W. and Cripps P. J. (1993) A survey of cardiac auscultatory findings in horses. Equine Vet. J. 25, 409-415

Pollock P. J., Russell T., Hughes T. K., Archer M. R. and Perkins J. D. (2008) Transpalpebral eye enucleation in 40 standing horses. Vet. Surg. 37, 306-309

Raffe M., Bistner S., Crimi A. and Ruff J. (1986) Retrobulbar block in combination with general anesthesia for equine ophthalmic surgery. Vet. Surg., 15, 139-141

Reef V. B. and Spencer P. (1987) echocardiographic evaluation of equine aortic regurgitation. Am. J. Vet. Res. 48, 904-909

Richey M. T., Holland M. S., McGrath C. J., Dodman N. H., Marshall D. B., Court M. H., Norman W. M. and Seeler D. C. (1990) Equine postanesthetic lameness. A retrospective study. Vet. Surg. 19, 392-397

Rubin L. F. (1964) Auriculopalpebral nerve block as an adjunct to the diagnosis and treatment of ocular inflammation in the horse. J. Am. Vet. Med. Assoc. 144, 1387-1388
Schauvliege S., van Loon G., De Clerca D., Devisscher L., Deprez P. and Gasthuys F. (2009) Cardiovascular responses to transvenous electrical cardioversion of atrial fibrillation in anaesthetized horses. Vet. Anaesth. Analg. 36, 341-351

Senior M. (2005) Post-anaesthetic pulmonary oedema in horses: a review. Vet. Anaesth. Analg., 32, 193-200

Senior J. M., Pinchbeck G. L., Allister R., Dugdale A. H., Clark L., Clutton R. E., Coumbe K., Dyson S. and Clegg P. D. (2007) Reported morbidities following 861 anaesthetics given at four equine hospitals. Vet. Rec. 24, 407-408

Short C. E. and Rebhun W. C. (1980) Complications caused by the oculocardiac reflex. J. Am. Vet. Med. Ass. 176, 630-631

Singh S., McDonell W. N., Young S. S. and Dyson D. H. (1996) Cardiopulmonary and gastrointestinal motility effects of xylazine/ketamine-induced anesthesia in horses previously treated with glycopyrrolate. Am. J. Vet. Res. 57, 1762-1770

Stevens K. B., Marr C. M., Horn J. N., Pfeiffer D. U., Perkins J. D., Bowen I. M., Allan E. J., Campbell J. and Elliott J. (2009) Effect of left-sided valvular regurgitation on mortality and causes of death among a population of middle-aged and older horses. Vet. Rec. 164, 904-909

Sweeney R. W., Reef V. B. and Reimer J. M. (1993) Pharmacokinetics of digoxin administered to horses with congestive heart failure. Am. J. Vet. Res. 54, 1108-1111

Thomas R. D., Behbehani M. M. and Coyle D. E. (1986) Cardiovascular toxicity of local anaesthetics: an alternative hypothesis. Anaesth Analg, 65, 444-450

Walker M. and Geiser D. (1986) Effects of acetylpromazine on the hemodynamics of the equine metatarsal artery, as determined by two-dimensional real-time and pulsed Doppler ultrasonography. Am. J. Vet. Res., 47, 1075-1078

Wilkie D. A. (1991) Ophthalmic procedures and surgery in the standing horse. Vet. Clin. North. Am. Equine. Pract. 7, 535-547

\author{
Dr. Klaus Hopster \\ Klinik für Pferde \\ Stiffung Tierärztliche Hochschule Hannover \\ Bünteweg 17, 30559 Hannover \\ Germany \\ klaus.hopster@tiho-hannover.de
}

